\title{
High serum potassium levels after losartan can reflect more severe renal disease. Reply to Gonçalves AR, El Nahas AM [letter]
}

\author{
S. S. Roscioni • Y. Miao • D. de Zeeuw • \\ H. J. Lambers Heerspink
}

Received: 23 June 2011 / Accepted: 12 August 2011 /Published online: 17 September 2011

(C) The Author(s) 2011. This article is published with open access at Springerlink.com

Keywords Diabetic nephropathy · End-stage renal disease · Hyperkalaemia, Losartan $\cdot$ Serum potassium

$\begin{array}{ll}\text { Abbreviations } \\ \text { ACEI } & \text { Angiotensin-converting enzyme inhibitor } \\ \text { ARB } & \text { Angiotensin receptor blocker } \\ \text { RAAS } & \text { Renin-angiotensin-aldosterone system } \\ \text { RENAAL } & \text { Reduction of Endpoints in NIDDM with the } \\ & \text { Angiotensin II Antagonist Losartan }\end{array}$

To the Editor: Gonçalves and El Nahas [1] raise interesting comments on our publication describing how blockade of the angiotensin I receptor with losartan increases serum potassium which is, in turn, associated with an increased risk of renal outcomes in patients with diabetes and nephropathy [2]. In their letter, Gonçalves and El Nahas suggest that those patients who developed hyperkalaemia were more likely to have pre-existing glomerular or tubulointerstitial damage, which could have accounted for the faster progression of renal disease. Although this could,

S. S. Roscioni $\cdot$ Y. Miao $\cdot$ D. de Zeeuw $\cdot$

H. J. Lambers Heerspink $(\bowtie)$

Department of Clinical Pharmacology,

University Medical Centre Groningen,

Antonius Deusinglaan 1,

9713 AV Groningen, the Netherlands

e-mail: h.j.lambers.heerspink@umcg.nl to a certain extent, hold true, we believe that such a theory does not explain our findings.

We performed various analyses to ensure that the relationship between increased serum potassium and renal outcome was independent of the severity of the underlying renal disease. First, we corrected for various renal risk markers, most notably the baseline and change in estimated glomerular filtration rate. Second, we conducted a pairmatched analysis selecting patients with similar characteristics who did and did not develop hyperkalaemia. Both analyses consistently showed that participants in whom serum potassium levels rose had a higher risk of renal disease. We therefore consider it unlikely that the greater degree of pre-existing renal injury in individuals who developed high serum potassium levels is the main factor responsible for their higher renal risk. Nevertheless, since neither glomerular nor tubulointerstitial damage was measured in the Reduction of Endpoints in NIDDM with the Angiotensin II Antagonist Losartan (RENAAL) trial, we cannot completely rule out the possibility that individuals who developed hyperkalaemia also had preexisting renal damage.

Further indirect evidence to support our hypothesis that the increase in serum potassium is associated with renal outcome stems from an additional analysis showing that adjustment of the losartan treatment effect for the residual potassium level (the serum potassium level during treatment) improves the overall renoprotective response to losartan. These data suggest that the increase in serum potassium during losartan therapy attenuates its long-term 
renoprotective effect and imply that improved management of hyperkalaemia may result in a better renal outcome. As mentioned by Gonçalves and El Nahas [1], it could still be possible that individuals who experienced high serum potassium levels received a higher dose of losartan. This hypothesis is, however, less likely because the dose of losartan was titrated towards $100 \mathrm{mg} /$ day in almost all patients. Gonçalves and El Nahas also suggested that those patients who experienced high serum potassium levels could have been more sensitive to a similar dose of losartan [1]. Nevertheless, this does not negate the fact that the development of high potassium levels appears to offset the renoprotective effect of losartan.

Given that both the short-term responses to losartan in terms of serum potassium levels and albuminuria are associated with renal outcomes, either positively (albuminuria) or negatively (potassium), Gonçalves and El Nahas [1] highlight the importance of evaluating the relationship between both of these responses within individual patients. Such a question is of clinical relevance since these opposing responses in individual patients may offer important insight into their ultimate renal outcome. In this regard, we performed additional analyses to investigate possible correlations between responses in serum potassium levels and albuminuria within each individual patient in the RENAAL trial. The majority of patients (52.6\%) showed a decrease in albuminuria and increase in serum potassium levels during treatment with losartan. However, a substantial number of patients experienced either reductions in both albuminuria and serum potassium levels (17.7\%), an increase in albuminuria and a decrease in serum potassium levels $(9.6 \%)$, or an increase in both variables $(20.0 \%)$. These data illustrate that the change in two variables in response to a single drug varies within an individual. The group of patients in whom both albuminuria and serum potassium rose, and thus had high residual albuminuria and high serum potassium levels during losartan therapy, had a very high risk of renal events, as shown in Fig. 1. However, our findings are based on a post hoc analysis, and a prospective evaluation is needed to prove that manipulation of serum potassium levels during angiotensin receptor blocker (ARB) therapy may result in improved renal outcomes. Nevertheless, these data clearly support the need for monitoring and optimising the response of serum potassium levels and albuminuria in individual patients to improve the long-term renal protective effects of ARBs.

Based on our observation that losartan treatment is associated with an increase in serum potassium levels, which increases renal risk, should we reconsider the continued use of inhibitors of the renin-angiotensin-

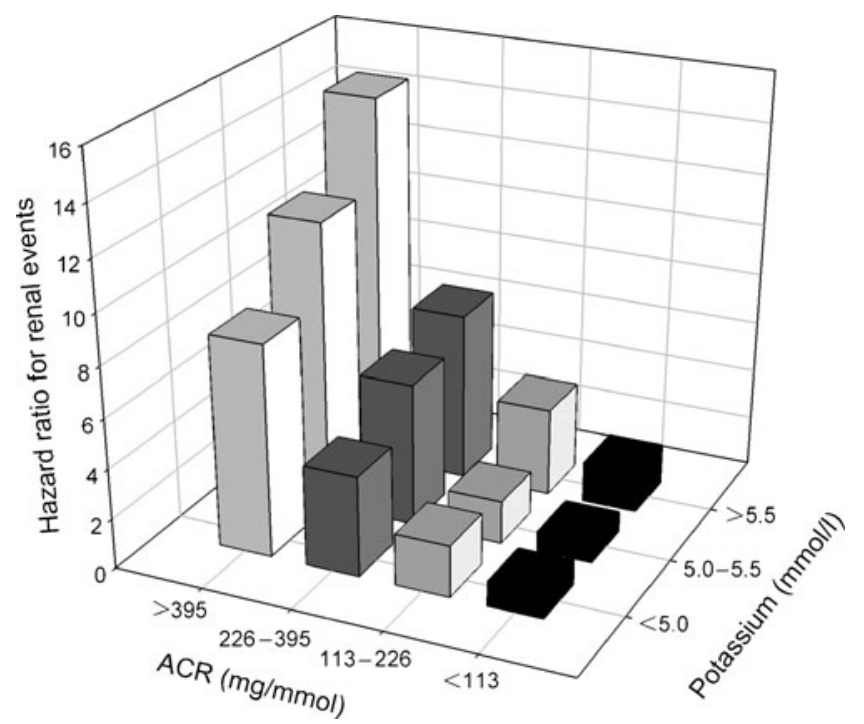

Fig. 1 Risk for renal events by mean levels of albuminuria (ACR) and serum potassium during follow-up. The figure shows that both the residual albuminuria and serum potassium determine the renal outcome. ACR, albumin to creatinine ratio. For conversion of ACR to $\mathrm{mg} / \mathrm{g}$, multiply by 8.84

aldosterone system (RAAS)? Gonçalves and El Nahas [1] indeed question the use of RAAS inhibitors and refer to the recent Ongoing Telmisartan Alone and in Combination with Ramipril Trial (ONTARGET), which showed increases in renal risk and hyperkalaemic events associated with combined angiotensin-converting enzyme inhibitor (ACEI) and ARB therapy compared with the single use of these agents [3]. However, given the proven renal and cardiovascular protective effects of ACEIs and ARBs in various populations (including those with diabetes and nephropathy) $[4,5]$, we strongly discourage the discontinuation of these agents. Instead, strategies to optimise the effect of a drug on the good surrogates, such as blood pressure and albuminuria, and to minimise its effect on the bad surrogates, such as serum potassium, are recommended. This approach may attenuate the high renal risk of the growing population of patients with diabetes and nephropathy.

Contribution statement All authors were responsible for data analysis and data interpretation. SS and HJLH drafted the article. $\mathrm{YM}$ and DdZ contributed with critical revisions of the publication. All authors approved the final version for publication.

Duality of interest The RENAAL study was funded by Merck \& Co. D. de Zeeuw has received financial support from Merck for his participation in the Steering Committee. The remaining authors declare that they have no duality of interest associated with this manuscript. 
Open Access This article is distributed under the terms of the Creative Commons Attribution Noncommercial License which permits any noncommercial use, distribution, and reproduction in any medium, provided the original author(s) and source are credited.

\section{References}

1. Gonçalves AR, El Nahas AM (2011) High serum potassium levels after using losartan can reflect more severe renal disease. Diabetologia doi:10.1007/s00125-011-2220-7

2. Miao Y, Dobre D, Heerspink HJ et al (2011) Increased serum potassium affects renal outcomes: a post hoc analysis of the
Reduction of Endpoints in NIDDM with the Angiotensin II Antagonist Losartan (RENAAL) trial. Diabetologia 54:44-50. Erratum 54:2209

3. Mann JF, Schmieder RE, McQueen M et al (2008) Renal outcomes with telmisartan, ramipril, or both, in people at high vascular risk (the ONTARGET study): a multicentre, randomised, double-blind, controlled trial. Lancet 372:547-553

4. Brenner BM, Cooper ME, de Zeeuw D et al (2001) Effects of losartan on renal and cardiovascular outcomes in patients with type 2 diabetes and nephropathy. N Engl J Med 345:861-869

5. Dahlof B, Devereux RB, Kjeldsen SE et al (2002) Cardiovascular morbidity and mortality in the Losartan Intervention For Endpoint reduction in hypertension study (LIFE): a randomised trial against atenolol. Lancet 359:995-1003 